\title{
Factors Affecting Level of Potato Commercialization in Kofale District, West Arsi Zone, Oromia Regional State, Ethiopia
}

\author{
Asfaw Negesse Senbeta \\ Department of Agricultural Economics Oromia Agricultural Research Institute Adami Tulu Research Center, Batu, Ethiopia \\ Email address: \\ bonsahu@gmail.com \\ To cite this article: \\ Asfaw Negesse Senbeta. Factors Affecting Level of Potato Commercialization in Kofale District, West Arsi Zone, Oromia Regional State, \\ Ethiopia. Journal of Investment and Management. Vol. 9, No. 2, 2020, pp. 56-62. doi: 10.11648/j.jim.20200902.13
}

Received: April 13,2020; Accepted: April 28, 2020; Published: August 5, 2020

\begin{abstract}
The Government of Ethiopia focuses on Agricultural Commercialization to meet the challenge of improving rural incomes by introducing Agricultural commercialization cluster. However, there are no adequate studies on level of commercialization and factors affecting Farmers' potato commercialization in Kofale District. This study was aimed to identify level and factors affecting farmers' level of potato commercialization. A two stage random sampling procedure was used to select 150 sample households potato producer. Descriptive statistics and econometric model were used to analyze the data. About $18 \%$ of sample farm households were low level of commercialization, about $15 \%$ medium and about $67 \%$ of them categorized under high level of commercialization. Truncated model was used in the econometric analysis. Education status, land allocated for Potato production and Access to market information influenced level of potato commercialization positively and significantly. The study indicated that the government, stakeholders and concerned bodies need to focus on facilitating farmers to participate education by providing adult education and extension based education, strengthening the existing livestock providing improved health services and better livestock feed (forage), improve productivity of land by providing technology and disseminate market information to producers so as to improve intensity of potato commercialization.
\end{abstract}

Keywords: Commercialization, Truncated Model, Household Commercialization Index and Kofale

\section{Introduction}

\subsection{Back Ground of the Study Area}

Agriculture is main economic pillars of the Ethiopian economy and the overall economic growth of the country is highly dependent on the success of the agriculture sector. The sector represents $38.5 \%$ of the GDP of the country and about $72.7 \%$ of the population gains their livelihood directly or indirectly from agricultural production. Crop and livestock subsectors accounted for $27.4 \%$ and $7.9 \%$ respectively. The total production of major crops by smallholder farmers during the Meher season (main season) increased to 270.3 million quintals. The performance of major crops has been the major contributor to overall growth in agriculture and allied activities during Growth and Transformation Plan I (GTP-I) plan period given its relative importance in crop production and agriculture at large [1].
Ethiopia's industrial strategy necessitates the establishment of industrial zones for agro-processing industries. Agroindustry can link up or integrate the agricultural sector which is the source of livelihood for the majority of Ethiopians. It can also create sustainable market link by establishing Rural Transformation Centers (RTC) that can improve production and productivity. One of the objectives of GTP-II is establishing Integrated Agro-industrial Parks (IAIPs) to link up the agricultural sector and add value to basic agricultural products [2].

In GTP-II period, agriculture expected to remain the main driver of the rapid and inclusive economic growth and development. It is also expected to be the main source of growth for the modern productive sectors. Therefore, besides promoting the productivity and quality of staple food crops production, special attention will also be given to cash crops, industrial inputs and export commodities. To this end, addressing constraints entrenched in the agricultural 
development and marketing systems is given utmost emphasis and priority [1].

\subsection{Statement of the Problem}

By encouraging the application of improved agricultural inputs and farming techniques, diversification out of lowyielding subsistence crops, and specialization in more tradable crops, commercialization can increase farming incomes, enhance purchasing power, and reduce vulnerability to food insecurity of smallholders. Commercialization of agriculture is, therefore, the strategy Ethiopia is following to bring dynamic change to transform the traditional agriculture of smallholder farmers [3].

The land use pattern of the kofale district shows that 33,599 ha is cultivable, 21,631 ha grazing land, 5,157 ha is covered by forest, bushes, and shrubs, and 5,913 ha is being used for other purposes such as encampments, and infrastructure facilities. From cultivated land about 7890 ha for potato production in 2017 production year. The district features a crop-livestock mixed farming system. Live stocks like cattle, sheep, donkey, horse, and poultry production were practiced in the study area. The types of crops widely grown in the district are barley, potato, maize, enset, normal cabbage (Etiopian kale) and head Cabbage. The main staple crops for food are enset, barley, maize, and potato while potato, head cabbage and malt barley for food and market [4].

As a food crop, potato has a high potential to supply quality food within a relatively short period, which in turn plays an important role in contributing to the household food security, nutritional value; generate income and employment opportunities for the poor households. Potato share $0.53 \%$ from all crops at national level as well as $29.21 \%$ coverage out of root crops. Potato production also contributes $19.90 \%$ to total root crop production at national level. The productivities of potato were 137.68 quintals per hectare. From root crops area coverage in the region, potatoes cover $43.97 \%$. West Arsi zone produced 21\% of root crops out of area coverage at regional level. From total area coverage by root crops potatoes cover about $86.86 \%$ in West Arsi Zone which major producers are Kofale and Shashamane Districts [5].

However, there is apparent knowledge gap as regards to factors influencing level commercialization of vegetable producers in general of potato growers in particular in study area. Therefore, identification of the factors affecting potato commercialization are crucial to improve their level of commercialization by providing information generated from this research work.

Objectives of the Study

The overall objective of this study was to analyze level and factors affecting level of potato commercialization in Kofele District.

The specific objectives of the study were:

1. To estimate farmers level of potato commercialization in Kofale District;

2. To identify factors affecting level of potato commercialize in Kofale District.

\section{Research Methodology}

\subsection{Description of the Study Area}

The study was conducted in Kofele district, West Arsi zone of Oromia National Regional State, Ethiopia. Kofele district is located at $305 \mathrm{~km}$ from Addis Ababa towards Southern direction. It shares borders with Shashemene district in the West, Kokosa district in the South, Gedab Asasa district in the East and Kore district in North directions. The district covers an area of 1187 square kilometers and has 38 rural and two urban Kebeles. From rural kebeles, 34 kebeles are high land while 4 kebeles are midland. The total population of the district were 207,339 (104,173 males and 103,166 females) having the rural population of 186,680 (93,100 males and 93,580 females), and urban population of 20,659 (11,073 males and 9,586 females) in which more than $65 \%$ depend on farming activities while the rest $35 \%$ of off and non-farm activities [4].

The major agro-ecologies of the district are high land (90\%) and mid-land (10\%) having clay loam soil type of $90 \%$ and the remaining $10 \% \mathrm{t}$ red and black. The district was found within 2460 to $2790 \mathrm{~m}-\mathrm{a}-\mathrm{s}-1$. It receives an average rainfall of 1800 $\mathrm{mm}$ per annum with minimum $2000 \mathrm{~mm}$ per annum and maximum $3050 \mathrm{~mm}$ per annum. The district has bi-modal rainfall distribution with small rains starting from March/April to May and the main rainy season extending from June to September/October. The average temperatures were $19.5^{\circ} \mathrm{C}$ per year with minimum of $17^{\circ} \mathrm{C}$ and maximum of $22^{\circ} \mathrm{C}$ [4].
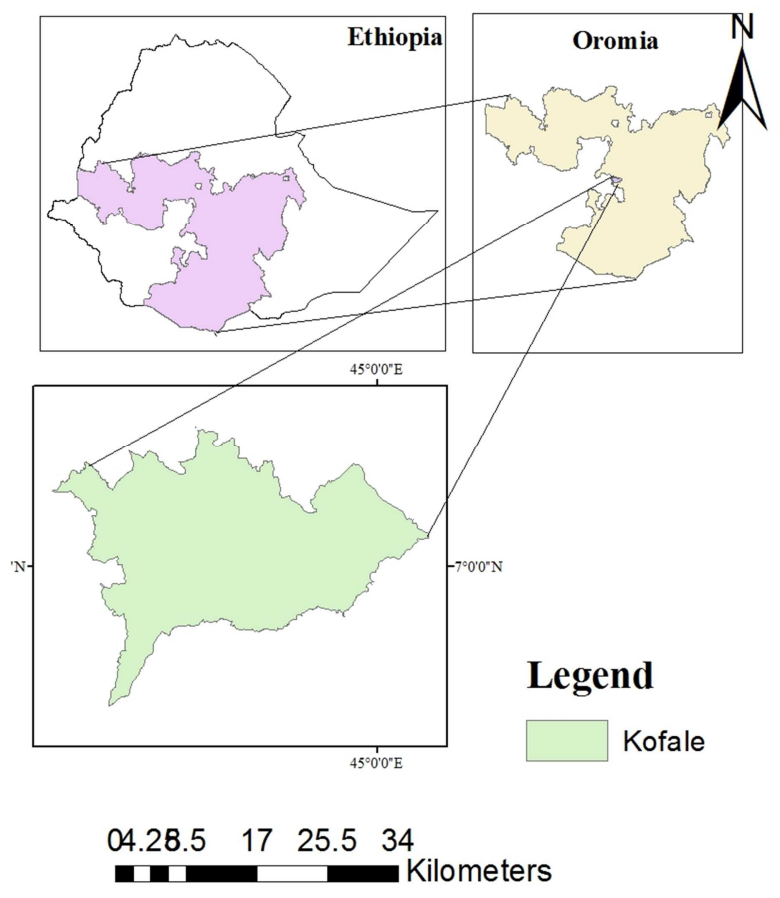

Source: Own sketch Arc map version 10.1, 2018.

Figure 1. Map of Kofale District. 


\subsection{Data Types, Sources and Methods of Data Collection}

Both qualitative and quantitative data were collected as well as primary and secondary data were used for this study. Semi-structured questionnaire was employed to collect primary data from representative sample of households. Secondary data relevant for this study was collected from Kofele District Office of Agriculture and Natural Resource, CSA, and from published and unpublished sources.

\subsection{Sampling Procedure and Sample Size}

The two-stage sampling procedure was used to select sample households. In the first stage, four sample Potato Producing kebeles were randomly identified in collaboration with concerned experts from district office of agriculture and development agents. In the second stages, 150 sample households were randomly selected from four sample kebeles based on probability proportional to size sampling technique.
Since the populations were homogenous the sample size was determined based on [6] formula:

$$
n=\frac{N}{1+N(e)^{2}}
$$

Where: $\mathrm{n}=$ is the sample of potato producer households that will be taken from potato producer households in the district, $\mathrm{N}=$ is the total number of potato producer households in the district and $\mathrm{e}=0.08$ is the level of precision.

The total number of households is 4340 , so sample size is calculated as follows:

$n=\frac{4340}{1+4340(0.08)^{2}}=\frac{4340}{28.8}=150$. Therefore, 150 sample households were selected randomly formal interview based on proportional to sample size of producers in peasant association (Table 1).

Table 1. Sampling frame and sample size.

\begin{tabular}{llll}
\hline Name of sampled kebeles & $\begin{array}{l}\text { Total potato producers households } \\
\text { (number) }\end{array}$ & $\begin{array}{l}\text { Proportion sampled Households } \\
\text { (\%) }\end{array}$ & $\begin{array}{l}\text { Number of sample household heads } \\
\text { (number) }\end{array}$ \\
\hline Germama & 719 & 28.67 & 43 \\
WamagnAlkeso & 619 & 24.67 & 37 \\
Koma Bitacha & 602 & 24 & 36 \\
Gurmicho & 568 & 22.67 & 34 \\
Total & 2508 & 100 & 150 \\
\hline
\end{tabular}

Source: DOANR and Own computation, 2018.

Methods of Data Analysis

Descriptive statistics and econometric model were used for analyzing the data.

Econometric model specification Descriptive

Commercialization index (CI) is used to analyze the level of potato output marketed. Here, the commercialization of potato production was analyzed from the output side. According to [7] and [8], commercialization index for crop production can be defined as:

$$
\mathrm{CIp}=\frac{\text { The gross value of all potato sales of hhi in yearj }}{\text { Gross value of all potato production of hhi in yearj }} \times 100 \%
$$

The index measures the ratio of the gross value of potato sales by the household $\mathrm{i}$ in year $\mathrm{j}$ to the gross value of all potato produced by the same household $i$ in the same year $j$ expressed as a percentage. CIp represents commercialization index of potato

The truncated regression model was used to analyze factors affecting the level (extent) of potato commercialization. Truncated regression excludes part of sample observation based on the value of the dependent variable [9]. As the result, the truncated regression model with the lower left truncation equal to 0 was used to determine factors influencing sales value of potato product. The intensity of potato commercialization is modeled as a regression truncated at zero:

$$
\begin{gathered}
\mathrm{Z}_{\mathrm{i}}^{*}=\mathrm{x}_{\mathrm{i}} \beta+\mu_{\mathrm{i}}, \mu_{\mathrm{i}} \sim \mathrm{N}\left(0, \delta^{2}\right) \\
\mathrm{Z}_{\mathrm{i}}=\left\{\begin{array}{c}
\mathrm{Z}_{\mathrm{i}}^{*} \text { if } \mathrm{Z}_{\mathrm{i}}^{*}>0 \text { and } Y_{i}=1 \\
0 \text { otherwise }
\end{array}\right\}
\end{gathered}
$$

Where $Z_{i}$ is the intensification level of commercialization which depends on latent variable $Z_{i}^{*}$ being greater than zero and conditional to the decision to commercialize $\mathrm{Y}_{\mathrm{i}}$.

If both decisions are made by the individual farmer independently, the error terms are assumed to be independently and normally distributed as: $u_{i} \sim N\left(0, \sigma^{2}\right)$

The log-likelihood functions as the double-hurdle model that nests a univariate probit model and a truncated regression model is given following [10] by:

$$
\log L=\sum \ln \left[1-\Phi\left(Z_{\mathrm{i}}^{\prime} \alpha\right)\left(\frac{x_{i}^{\prime} \beta}{\sigma}\right)\right]+\sum_{+} \ln \left[\Phi\left(Z_{i}^{\prime} \alpha\right) \frac{1}{\sigma} \phi\left(\frac{y_{i}-x_{i}^{\prime} \beta}{\sigma}\right)\right]
$$

Where, $\Phi$ and $\phi$ refer to the standard normal probability and density functions respectively, $Z_{i}^{\prime}$ and $X_{i}^{\prime}$ represent 
independent variables for the Probit model and the Truncated model respectively, $\alpha, \sigma$, and $\beta$ are parameters to be estimated for each model.

Table 2. Summary of variables description and hypothesis.

\begin{tabular}{lll}
\hline Dependent Variables & Unit/ type & Variables Description \\
\hline Level of Commercialization & Continuous & value of potato sold in Ethiopian Birr \\
Explanatory Variables Description of variables & & Dummy, 1 for male and 0 for female \\
Gender & Continuous, experience potato production in years \\
Farming Experience & Continuous, land allocated in hectares \\
Land under production & Continuous, education status years of schooling \\
Education & Continuous, number of family members living together \\
Family size & Continuous, in kilometres \\
Distance to market center & Dummy, Yes=1, $0=$ No \\
Access to market information & Continuous, number of extension contact \\
Frequency of extension contact & Dummy, Yes $=1,0=$ No \\
Access to credit service & Dummy, Yes=1, $0=$ No \\
Participation in farmer groups & Continuous, tropical livestock unit \\
Livestock owned & Dummy, Yes $=1,0=$ No \\
Off and non-farm income & + \\
\hline
\end{tabular}

\section{Results and Discussion}

\subsection{Summary of Descriptive Statistics}

Table 3. Summary of descriptive statistics.

\begin{tabular}{llll}
\hline No & Continues Variables & Mean & Std. Dev. \\
\hline 1 & Farming experience (Years) & 13.02 & 7.77 \\
2 & Family Size (Numbers) & 8.77 & 3.90 \\
3 & Livestock holding (TLU) & 7.91 & 3.92 \\
4 & Land allocated for production & 0.46 & 0.20 \\
5 & Distance to market center & 4.35 & 0.70 \\
6 & Commercialization index & 57.77 & 27.29 \\
\hline
\end{tabular}

\begin{tabular}{llll}
\hline \multirow{2}{*}{ No } & \multirow{2}{*}{ Dummy variable } & Percent & \\
\cline { 3 - 4 } & & Yes & No \\
\hline 1 & Sex & 91.33 & 8.67 \\
2 & Participation social organization & 60 & 40 \\
3 & Access to extension service & 55.33 & 44.67 \\
4 & Access to credit service & 36 & 64 \\
5 & Educational status & 90 & 10 \\
6 & Participation in non/off farm activities & 19.33 & 80.67 \\
\hline
\end{tabular}

Source: Own survey result, 2018

The results of descriptive statistics analysis indicated that about 100 sample households (66.67\%) was commercialized potato and the average intensity of potato commercialization was $57.77 \%$ that implied more than half of the farmers in the study area commercialized potato production. The mean farming experience of the sample respondents was about 13.02 years. The average number of family size for the sample respondents were about 8.7 and about $91 \%$ respondents were male households. The average land size allotted under potato per sample household head was about 1.34 hectares which less than two hectares while the mean livestock possession was about 7.91 TLU (Table A1) that implies livestock is the main contribution in the study area. The average distance market center from farm gate was 4.35 kilometers. The sample households in study area are sale their product at farm gate, as a result there is a problem of road directly connects from farm site to all-weather road and only about $19.33 \%$ participated in non/off-farm activities. About $90 \%$ of sample households were literate and $10 \%$ illiterate that implied literate households are easily understand extension service to adopt technology. About $55.33 \%$ of sample respondents' access to extension service by different extension service providers (Table 3 ).

\subsection{Household Level of Potato Commercialization}

The degree of household commercialization in the study area ranged from 0 to 1 across the sampled households. As shown in Table 1, about $67 \%$ of households found to be at higher level of commercialization, selling on average $74.19 \%$ of the total quantity of the produce, whereas $23 \%$ and $27 \%$ of the households are at medium and low commercialization level, with average sell of $43.48 \%$ and $9.12 \%$ of the produce, respectively (Table 4). In general the level of household commercialization in the study area was found to be $60 \%$, which is significantly above the national commercialization average 5\% [11-12].

Table 4. Household Level commercialization Index.

\begin{tabular}{llll}
\hline Level of commercialization & Frequency & Percent & HCI \\
\hline Low $(0-0.3)$ & 27 & 18 & 9.12 \\
Medium $(0.31-0.5)$ & 23 & 15 & 43.48 \\
High $(0.51-1.0)$ & 100 & 67 & 74.19 \\
Total & 150 & 100 & 57.77 \\
\hline
\end{tabular}

Source: Own calculation, Survey data, 2018

\subsection{Factors Affecting Smallholder Farmers' Level of Potato Commercialization}

The model specification was carried out using the Ramseyreset test, and the result is insignificant (prob $>\mathrm{F}=0.421$ and 0.475 for potato and head cabbage respectively) indicating that there were no problem of omitted variables in the model for both commodities. Variance inflation factors (VIF) was computed for all explanatory variables that are used in the Probit model and the result shows VIF values of less than 10 indicating multicollinearity was not a problem (Table A2). Robust method was also employed to correct the possible 
problem of heteroscedasticity. Outliers were checked using the box plot graph so that there were no serious problems of outliers and no data get lost due to outliers.

The truncated model result shows that the model statistically significant at $1 \%$ level of significance, indicating the goodness of fit of the model to explain the effects of the hypothesized variables on the dependent variable in terms of at least one covariate. The estimation result also revealed that the intensity of farmers' potato commercialization was influenced significantly by Education status, livestock holding, land allocated for potato production and Access to market information (Table 5).

Table 5. Factors affecting sample households' level of potato commercialization.

\begin{tabular}{llll}
\hline Variables & Coefficient & Robust Std. Err & P $>\mathbf{z}$ \\
\hline Farming Experience & -295.35 & 251.45 & 0.240 \\
Gender & 5383.90 & 7188.42 & 554.48 \\
Education status & $1032.78^{*}$ & 511.10 & 0.454 \\
Total Family size & 641.57 & 464.76 & 0.063 \\
Livestock holdings (TLU) & $812.29 *$ & 15000.46 & 0.209 \\
Land for potato production & $82761.41^{* * *}$ & 4290.82 & 0.081 \\
Frequency of extension contact & -790.15 & 3277.23 & 0.000 \\
Access to credit service & -692.06 & 4238.34 & 0.854 \\
Access to market information & $9472.67 * *$ & 900.68 & 0.833 \\
Distance to all weather road & -836.67 & 4889.70 & 0.025 \\
Participation in social organization & 7273.53 & 16153.51 & 0.353 \\
Constant & $-65849.21^{* * *}$ & 1446.39 & 0.137 \\
Sigma & $11720.86^{* * *}$ & 0.000 \\
\hline
\end{tabular}

***, *: implies statistical significance at $1 \%, 5 \%$, and $10 \%$ levels, Log pseudo likelihood $=-1338.59$, Wald chi ${ }^{2}(11)=48.72$, Prob $^{2}$ chi $^{2}=0.0000, \mathrm{~N}=133$, Limit: lower $=0$, upper $=+$ inf, Source: model result, 2018.

Educational status (Educ): Education is found to have a positive and significant influenced on farmers' level of potato commercialization at $10 \%$ level of significance. This result implies that on average, literate household earn about 1032.78 ETB (Ethiopian Birr) more as compared to illiterate household head from sales of Potatoes, keeping all other factors constant because of education enhances the skill and ability to better utilize market information, which may reduce marketing costs and make it more profitable from commercialization. This result in line with the findings of [13].

Livestock holdings Livestock holdings: Livestock possession was also found to be positively influence the level of Potato commercialization and statistically significant at $10 \%$ level. The positive coefficient of livestock possession implies that an increase in livestock possession by one TLU [14] would increase the value of potato output the household sold by about 812.29 Ethiopian Birr (ETB). One reason could be that, livestock provides manures as manure is the main nutrient used by farmers for crop production in study area and livestock are the main source for this nutrient, the increase in the number of livestock owned would improve the potato productivity and hence increases the marketable surpluses. This is consistent with the findings of Aman [13] which suggest that farmers with more livestock tend to have higher market integration.

Size of land allocated for potato production: Size of land allocated for potato production is found to have a positive and significant influenced on farmers' level of potato commercialization at $1 \%$ level of significance. This is expected since land is a critical production asset having a direct bearing on production of surplus due to economies of scale. An additional one hectare (1ha) of the household allocate for potato production would increase the value of potato output sold by about ETB 82,761.40 ETB (Ethiopian Birr). This is consistent with the findings of [15], increase in cultivated land size may have boosted production of horticultural crops and also consistent with the government's massive push to promote and deliver technology packages to smallholders.

Access to market information: Access to market information was found to have a positive and significant influenced on farmers level of Potato commercialization at $5 \%$ level of significance. This significance indicating that farmer accessed to market information about Potato marketing is more likely to commercialize Potato than others. The result implies that on average, Potato producer farmer whose access to market information earn about 9,472.67ETB (Ethiopian Birr) more as compared to farmer whose not access to market information from sales of Production of Potatoes from hectares of land, keeping all other factors constant, which implies that households with better information access can reduce market and transaction cost. This is in line with the finding of Kumilachew [16].

\section{Conclusions and Recommendations}

\subsection{Conclusions}

Even though agricultural commercialization is considered as the main engine to contribute to economic growth of the country and to transform the traditional agriculture of farmers the extent of commercialization is still not as expected in Ethiopia as evidenced from different literature. Government of Ethiopia introduce agricultural commercialization cluster to enhance commercialization behavior of farmers. Even though government concern there is no sufficient study on commercialization specifically in Kofale District. Therefore, 
study was to analyze level of commercialization and factors influencing farmers' intensity of potato commercialization. The average intensity of potato commercialization was 57.77 percent. About $18 \%$ of sample farm households were low level of commercialization, about $15 \%$ and $67 \%$ of them categorized under medium and high level of commercialization respectively.

The result of truncated model revealed that out of total 11 explanatory variables included in the model. Total of four variables found significantly affected sample farmers' level of potato commercialization. To this effect, Education status, livestock holding, Area allocated for potato production, and Access to market information which were positively influenced households' level of potato commercialization.

\subsection{Recommendations}

Based on the findings of this study, the following recommendations are made.

Land allocated to potato productions significantly affected farmers' level of potato commercialization so farmers better to increase the land productivities by using organic fertilizers and increase management practice for both commodities to increase their level of potato commercialization.

Livestock holding significantly affected sample level of potato commercialization positively. The study suggested strengthening the existing livestock providing improved health services, better livestock feed (forage), targeted credit and adopting agro-ecologically based high-yielding breeds and disseminating through artificial insemination in Kofale District.

The education of the household head also plays a prominent role in the intensity of potato sales, thus, Agricultural Development and Natural Development Office should aim in upgrading the knowledge of the household head through extension based training and adult education.

Access to market information significantly affected farmers' level of potato commercialization positively. The government should give price and market information by different means of information providers' instruments as well as create market integration to enhance farmers' level of potato commercialization.

\section{Appendix}

Table A1. Conversion factors used to compute Tropical livestock Units (TLU).

\begin{tabular}{ll}
\hline Livestock Categories & Conversion factor \\
\hline Cow/Ox & 1 \\
Bull & 0.75 \\
Heifer & 0.75 \\
Calf & 0.2 \\
Horse/Mule & 1.1 \\
Camel & 1.25 \\
Sheep/Goat & 0.13 \\
Donkey & 0.7 \\
Poultry & 0.013 \\
\hline
\end{tabular}

Source: Stork et al., 1991
Table A2. Multicollinearity test.

\begin{tabular}{lll}
\hline Variables & VIF & 1/VIF \\
\hline Age & 1.73 & 0.577432 \\
TFSZ & 1.66 & 0.603342 \\
TLU & 1.60 & 0.623536 \\
Ecuc & 1.59 & 0.630095 \\
Extefreq & 1.54 & 0.648020 \\
AMInformation & 1.46 & 0.685932 \\
TLPP & 1.42 & 0.704193 \\
Sex & 1.38 & 0.725603 \\
Social & 1.34 & 0.746945 \\
Pnonoff-farm & 1.23 & 0.811434 \\
DMarkNcenter & 1.17 & 0.854345 \\
Acredit & 1.12 & 0.896481 \\
Mean VIF & 1.44 & \\
\hline
\end{tabular}

\section{References}

[1] NPC (National Plan Commission). 2016. Growth and Transformation Plan II (GTP II), National Plan Commission Volume I: Main text Addis Ababa.

[2] Abiy Hailu. 2016. Ethiopia: IAIPs -Epicenter for agricultural commercialization. The Ethiopian herald (Addis Ababa), Ethiopia.

[3] Afework Hagos and Endrias Geta. 2016. Review on smallholder agriculture commercialization in Ethiopia: What are the driving factors to focus on? Journal of Development and Agricultural Economics, 8 (4): 65-76.

[4] DOANR (District Office of Agriculture and Natural Resource). 2018. Reports of Kofale district Office of Agriculture and Natural Resource, 2018. Kofale, Ethiopia.

[5] CSA (Central Statistical Agency). 2017. The Federal Democratic Republic of Ethiopia central Statistical Agency agricultural sample survey report on area and production of major crops 584 Statistical Bulletin 2016/2017 (2009 E. C.) Volume I

[6] Yamane., T. 1967. Statistics: An introductory analysis, $2^{\text {nd }}$ Ed., New York: Harper and Row.

[7] Strasberg, P. J., Jayne, T. S., Yamano, T., Nyoro, J., Karanja, D., Strauss, J. 1999. Effects of agricultural commercialization on food crop input use and productivity in Kenya. Office of Sustainable Development; Policy Synthesis for USAID-Africa Bureau, pp. 41.

[8] VonBruan., J and Kennedy., E. 1994. Agricultural commercialization, economic development and Nutrition (Baltimore: John Hopkins University Press)

[9] Wooldridge., J. W. 2002. Econometric analysis of cross section and panel data. Cambridge, the MIT Press, Cambridge, Massachusetts, London, England.

[10] Cragg, J. 1971. Some statistical models for limited dependent variables with application to the demand for durable goods. Econometrica, 39 (5): 829-844.

[11] EEA (2006). Evaluation of the Ethiopian agricultural extension with particular emphasis on the Participatory Demonstration and Training Extension System. Research Report, Ethiopian Economic Association, Addis Ababa, Ethiopia.

[12] Gebre-ab N (2006). Commercialization of small holder agriculture in Ethiopia. Note and Papers Series 3. 
[13] Aman Tufa, Adam Bekele and Lemma Zemedu. 2014. Determinants of smallholder commercialization of horticultural crops in Gemechis district, West Hararghe zone, Ethiopia. African Journal of Agricultural Research, 9 (3): 310-319.

[14] Stork, H., Bezabih Emana, Berhanu Adnew, Borowiecki, A A. and Shimelis Woldehawariat. 1991. Farming systems and farm management practices of smallholders in the Hararghe Highlands. Farming system and resource economics in the Tropics. 11: Wissenschafts Varlag Vauk Kiel KG, Germany.
[15] Angula M (2010). Determinants of sustainable coffee marketing channel choice and supply response among organic and certified smallholder farmers: Evidence from Uganda. A thesis submitted in partial fulfillment of the requirements for the degree of Master of Science of Agricultural, food and resource economics. Michigan State University.

[16] Kumilachew Alamerie Melesse. 2016. Commercial behaviour of smallholder potato producers: the case of Kombolcha woreda, eastern part of Ethiopia. UDC 633.49: 631.1.017.3: $330.13(63)$. 